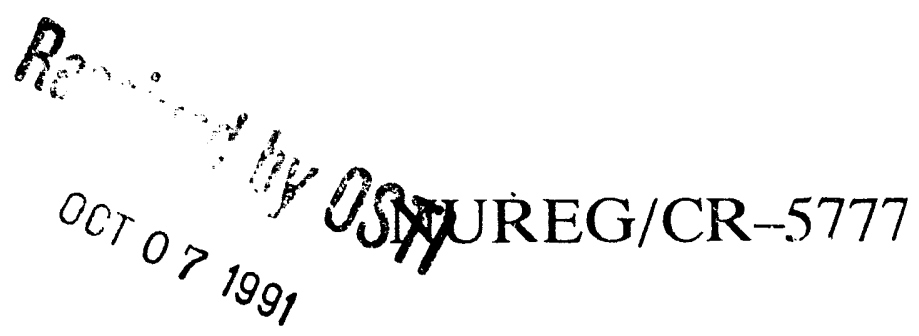

\title{
Global Positioning System
}

Measurements Over a Strain

Monitoring Network in the

Eastern Two-Thirds of the

United States

Prepared by

W. E. Strange

National Geodetic Survey

National Oceanic and Atmospheric Administration

Prepared for

U.S. Nuclear Regulatory Commission 


\section{AVAILABIUTY NOTICE}

Availability of Reference Materials Crted in NRC Publications

Most documents clted In NRC publications will be avalable from one of the following sources:

1. The NRC Public Document Room, 2120 L Street, NW., Lower Level, Washington, DC 20555

2. The Superintendent of Documents, U.S. Government Printing Office, P.O. Box 37082, Washington, DC 20013-7082

3. The National Technical Information Service, Springfield, VA 22161

Although the Hsting that follows represents the majortty of documents cited in NRC publications, it is not intended to be exhaustive.

Referenced documents avalable for Inspection and copying for a fee from the NRC Public Document Room include NRC correspondence and internal NRC memoranda; NRC bulletins, circulars, information notices. Inspection and investigation notices: licensee event reports; vendor reports and correspondence; Commisslon papers; and applicant and licensee documents and correspondence.

The following documents in the NUREG series are avallable for purchase from the GPO Sales Program: formal NRC staff and contractor reports. NRC-sponsored conference proceedings, and NRC booklets and brochures. Also avallable are regulatory guides, NRC regulations in the Code of Federal Regulations, and Nuclear Regulatory Commission Issuances.

Documents avallable from the National Technical Information Service include NUREG-series reports and technical reports prepared by other Federal agencies and reports prepared by the Atomic Energy Commission. forerunner agency to the Nuclear Regulatory Commission.

Documents avallable from public and special technical libraries include all open literature items, such as books, Journal articles, and transactions. Federal Register notices. Federal and State legislation. and congressional reports can usually be obtained from these libraries.

Documents such as theses, dissertations, foreign reports and translations, and non-NRC conference proceedings are available for purchase from the organization sponsoring the publication cited.

Single coples of NRC draft reports are avallable free, to the extent of supply, upon written request to the Office of Administration. Distrlbution and Mall Servises Section, U.S. Nuclear Regulatory Commission, Washington, DC 20555.

Coples of industry codes and standards used in a substantive manner in the NRC regulatory process are maint ained at the NRC Library, 7920 Norfolk Avenue. Bethesda, Maryland, for use by the public. Codes and standards are usually copyrighted and may be purchased from the originating organization or. If they are American National Standards, from the American National Standards Institute, 1430 Broadway. New York. NY 10018

\section{DISCLAIMER NOTICE}

This report was prepared as an account of work sponsored by an agency of the United States Government. Neither the United States Government nor any agency thereof, or any of their employees, makes any warranty. expressed or implied, or assumes any legal liability of responsibility for any third party's use, or the results of such use, of any information, apparatus, product or process disclosed in this report, or represents that its use by such third party would not infringe privately owned rights. 


\section{Global Positioning System Measurements Over a Strain Monitoring Network in the Eastern Two-Thirds of the United States}

Manuscript Completed: August 1991

Date Published: September 1991

Prepared by

W. E. Strange

National Geodetic Survey

National Oceanic and Atmospheric Administration 11400 Rockville Pike

Rockville, MD 20852

Prepared for

Division of Engineering

Office of Nuclear Regulatory Research

U.S. Nuclear Regulatory Commission

Washington, DC 20555

NRC FIN D1749

Under Interagency Agreement No. RES-87-005 


\begin{abstract}
A 45-station geodetic network was established in 1987 using global positioning system (GPS) technology. The objective of this network is to provide a means of monitoring strain and deformation in the central and eastern United States. Reduction of the initial epoch data showed that accuracies of 1 to $3 \mathrm{~cm}$ can be achieved for horizontal positioning provided sufficient observations are available and there are four or more fiducial stations whose positions are known a priori, for example from Very Long Baseline Interferometry (VLBI) measurements, and can be used to perform orbit improvement computations. Given the station separations involved the accuracies obtained provide the ability to determine strain at the $1: 10^{7}$ to $1: 10^{8}$ level. Vertical positions are less accurate because of problems in modeling refraction and are determined at the 5 to $7 \mathrm{~cm}$ level. It is planned to remeasure this network at regular intervals in the coming years to place bounds on the strain occurring in the central and eastern United States. This network is also expected to serve as a reference network for more detailed monitoring networks in areas of high risk such as the New Madrid area. Future measurements are expected to provide more accurate results because of increased numbers of GPS satellites available and improved computation software. The improved software will also allow future upgrading of the accuracy of the 1987 observations. Ultimately this network should allow strain monitoring of the central and eastern United States at the 1 to $2: 10^{8}$ level.
\end{abstract}


TABLE OF CONTENTS

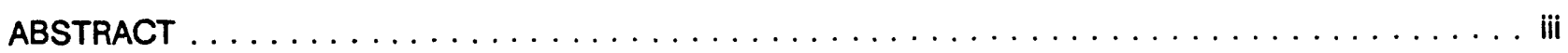

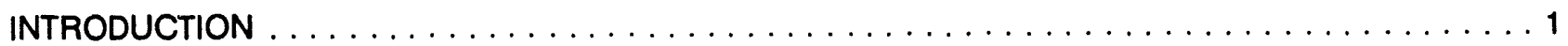

NETWORK PLANNING AND RATIONALE $\ldots \ldots \ldots \ldots \ldots \ldots \ldots \ldots \ldots \ldots \ldots \ldots \ldots \ldots$

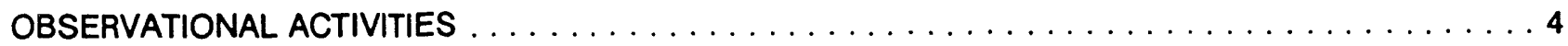

GENERAL CHARACTERISTICS OF SOLUTION $\ldots \ldots \ldots \ldots \ldots \ldots \ldots \ldots \ldots \ldots \ldots \ldots$

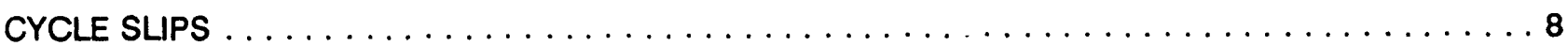

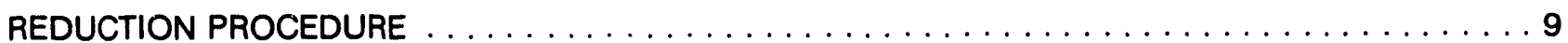

DESCRIPTION OF RESULTS $\ldots \ldots \ldots \ldots \ldots \ldots \ldots \ldots \ldots \ldots \ldots \ldots \ldots \ldots$

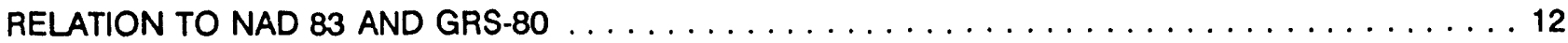

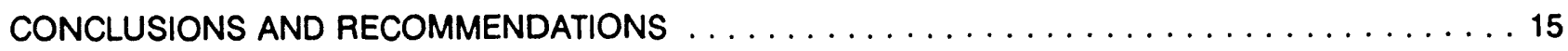

APPENDIX - STATION POSITIONS AND LINE LENGTHS $\ldots \ldots \ldots \ldots \ldots \ldots \ldots \ldots \ldots \ldots$ 
1. EASTERN U.S. STRAIN NETWORK $\ldots \ldots \ldots \ldots \ldots \ldots \ldots \ldots \ldots \ldots \ldots \ldots \ldots \ldots \ldots \ldots$

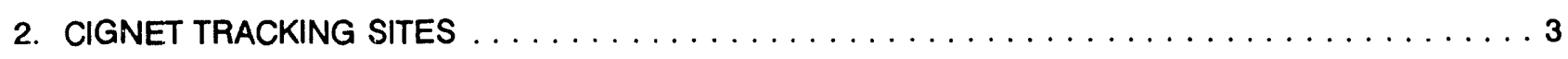

3. REPEATABILITY OF DETERMINATIONS $\ldots \ldots \ldots \ldots \ldots \ldots \ldots \ldots \ldots \ldots \ldots \ldots \ldots$

\section{LIST OF TABLES}

1. STATIONS OF THE EASTERN U.S. STRAIN NETWORK $\ldots \ldots \ldots \ldots \ldots \ldots \ldots \ldots \ldots \ldots \ldots$

2. OBSERVING SCENARIO AND SATELLITE AVAILABILITY $\ldots \ldots \ldots \ldots \ldots \ldots \ldots \ldots$

3. STATION OCCUPATIONS SEPTEMBER/OCTOBEF $1988 \ldots \ldots \ldots \ldots \ldots \ldots \ldots \ldots \ldots$

4. REFERENCE STATIONS USED FOR SOLUTIONS $\ldots \ldots \ldots \ldots \ldots \ldots \ldots \ldots \ldots \ldots \ldots$

5. DIFFERENCES BETWEEN MEAN GPS AND VLBI POSITIONS $\ldots \ldots \ldots \ldots \ldots \ldots \ldots \ldots \ldots$

6. TRANSFORMATION PARAMETERS $\ldots \ldots \ldots \ldots \ldots \ldots \ldots \ldots \ldots \ldots \ldots \ldots \ldots \ldots \ldots \ldots$

APPENDIX

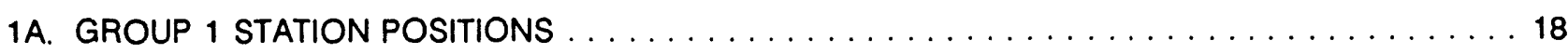

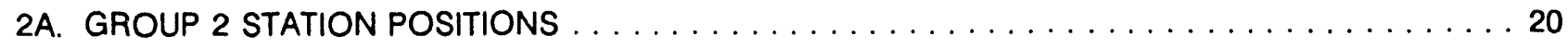

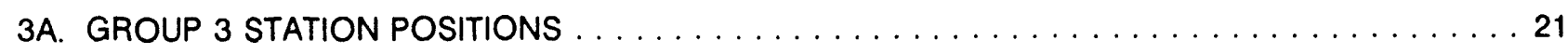

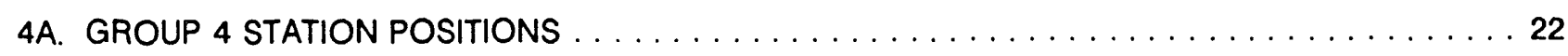

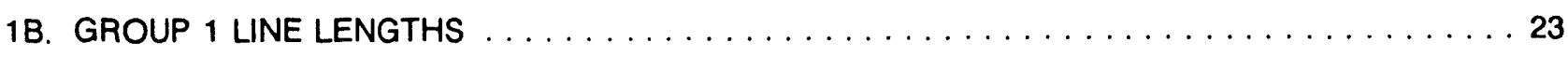

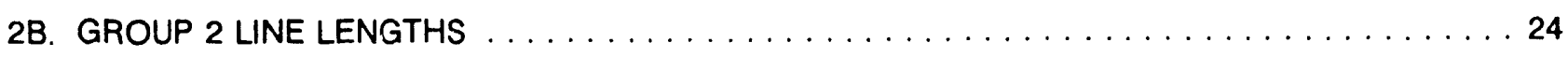

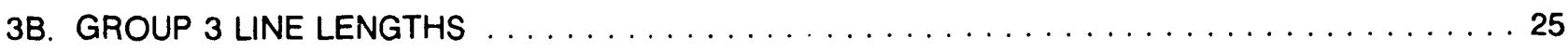

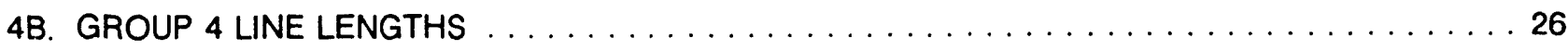

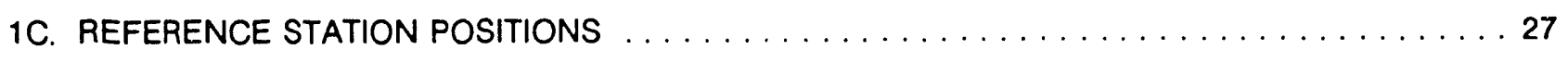




\section{INTRODUCTION}

In November and December of 1987, the National Geodetic Survey (NGS) undertook the establishment of a 45-station Global Positioning System (GPS) network covering the United States approximately east of $105^{\circ}$ west longitude (Figure 1). This network was established in support of the Nuclear Regulatory Commission (NRC) for the purpose of monitoring crustal strain in the area. GPS technology was used to perform measurements over this network. In addition to monitoring large-scale strain, the network will provide a basic framework to support more detailed GPS networks (established for geodynamic and surveying applications) which can monitor strain and deformation in the central and eastern United States.

The determination of strain with this 45 station network, which we have designated the Eastern $U$. S. Strain Network, is a long-term effort, with repeated observations made over a time period of a decade or more. Strains and deformations in this region are expected to be very small. Therefore, accuracy objectives for the survey were set at 1:107 or better. As a practical matter, accuracies of distances between stations would need to be at the few centimeters level to be useful for secular strain rate determinations in the eastern United States. Thus, for longer Daselines ( $>500 \mathrm{~km})$, accuracies of a few parts in $10^{8}$ will be needed to provide useful strain determination results.

\section{NETWORK PLANNING AND RATIONALE}

The stations of the Eastern United States Strain Network were located based on four primary criteria.

(1) Stations were to be distributed over the entire area east of the Rocky Mountains.

(2) Stations were to be somewhat denser in areas of special interest, such as the New Madrid and Charleston areas.

(3) Stations were located so as to span areas of potentially significant seismicity and deformation.

(4) Stations of the network were to be collocated with stations of the Cooperative International GPS Network (CIGNET), and with existing Very Long Baseline Interferometry (VLBI) stations in the area.

Table 1 summarizes the stations selected for the Eastern U. S. Strain Network.

Collocation with stations of the GPS orbit determination network, CIGNET, and with VLBI stations was felt to be extrer:ely important for three reasons. First, long-term monitoring with high accuracy using GPS requires connection to an earth fixed coordinate system, which can be monitored with very high accuracy over time. Second, to validate the accuracy of the GPS results, a second technique must be available at a subset of the strain network stations for comparison purposes. Finally, to obtain results of satisfactory accuracy using GPS, at least four stations of a GPS observing network should have positions known a priori and held fixed during solutions, to permit orbit improvement of the GPS satellite orbits.

In order to compute orbits for GPS satellites for use by the civil community NGS, working within the context of the International Union of Geodesy and Geophysics (IUGG), has, together with organizations in a number of foreign countries, initiated formation of a Cooperative International GPS Network (CIGNET). Currently, there are 9 CIGNET stations, all located in the northern hemisphere (Figure 2). Until such time as CIGNET stations are established in the southern hemisphere, NGS has an agreement with the Defense Mapping Agency (DMA) to obtain GPS tracking data from the 5 station DMA network, including 3 southern hemisphere stations (Figure 2). NGS operates 4 of the 9 CIGNET stations. Three 


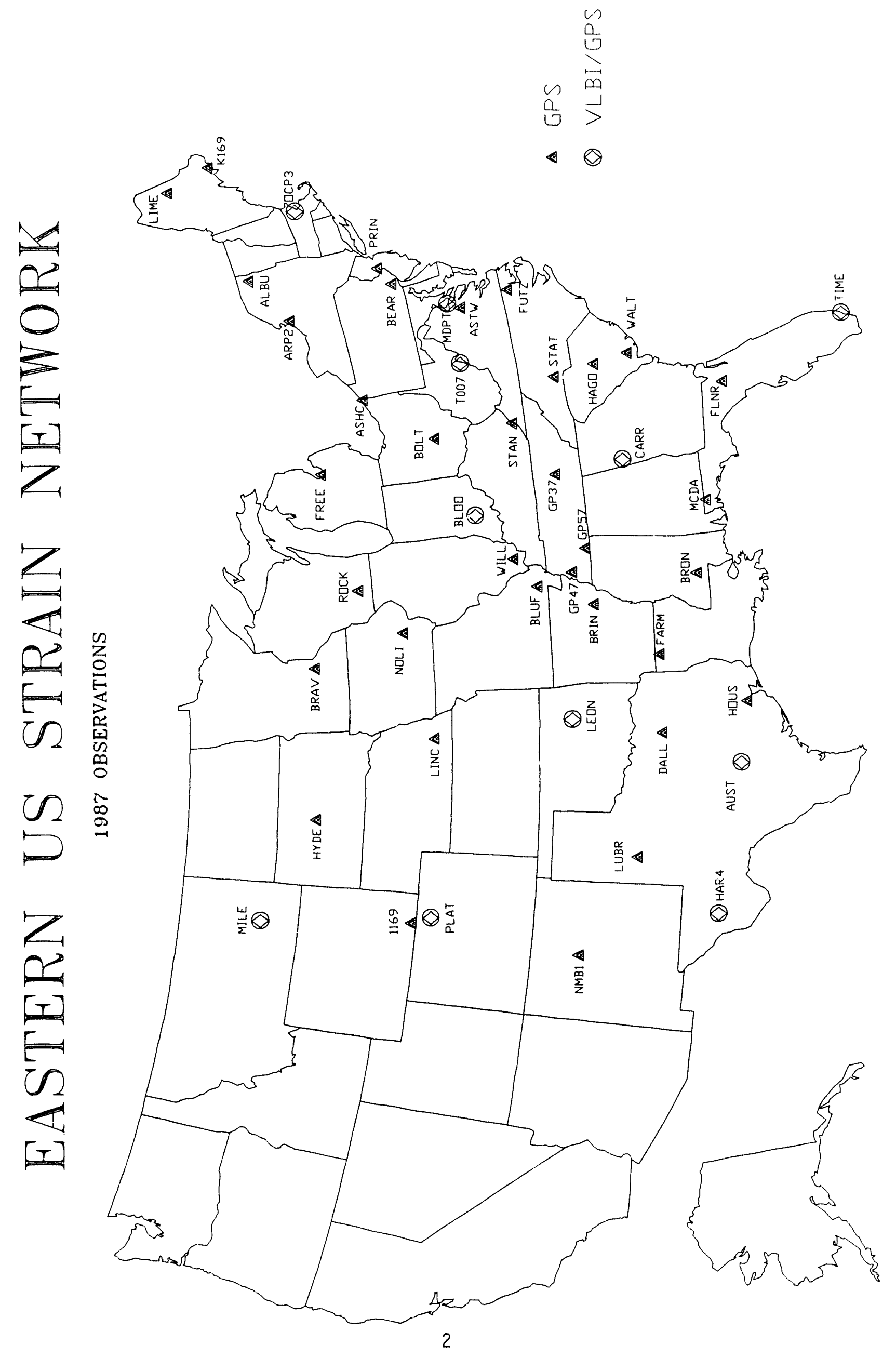

-1
0
$\frac{0}{3}$
章 


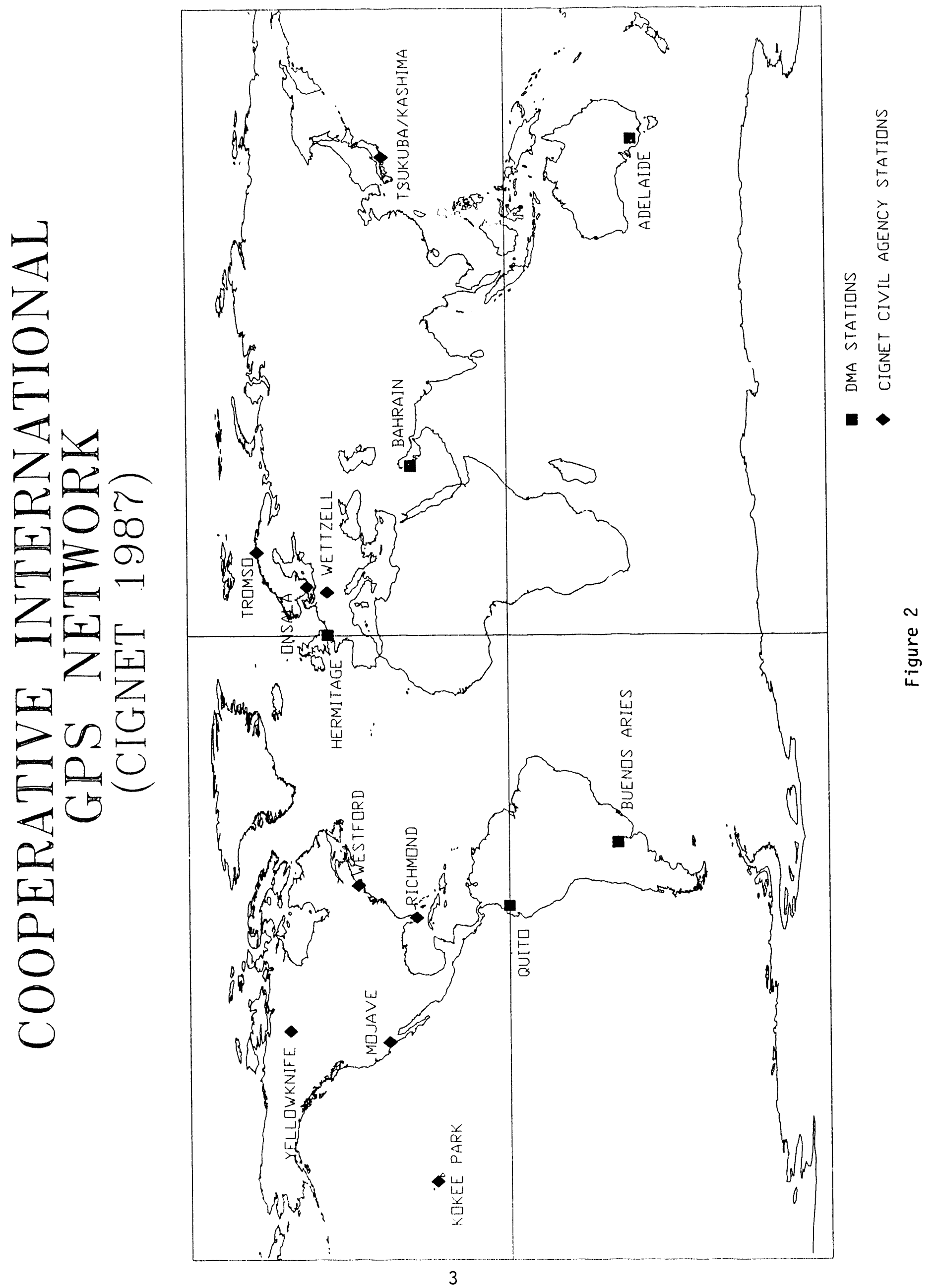


are in the conterminous 48 states (Westford, MA; Richmond, FL; and Mojave, CA), and one in Hawail. The Westford and Richmond stations were included in the strain network. Although the Mojave station is not a part of the strain network, data from this station (as will be discussed elsewhere in this report) were used to support orbit adjustment during data reduction.

VLBI is a technique which uses radio telescopes (dish antennas) to monitor incoming radio frequency signals from quasars and other celestial objects. Using these signals, it is possible to determine differeritial positions between telescopes at the centimeter level, even with station separations of thousands of miles, and to derive information on earth orientation (earth rotation, polar motion, precession, and nutation) with extremely high accuracy. VLBI receivers (radio telescopes) can be either fixed or mobile. Within the coterminous 48 states, NGS operates 4 fixed VLBI receivers, located at Westford, MA; Richmond, FL; Mojave, CA; and Ft. Davis, TX. All of these have contributed to the International Earth Rotation Service (IERS), which provides earth orientation services. In addition, fixed VLBI stations are operated by U. S. Navy components at Maryland Point, MD and Greenbank, WV. Collocated GPS stations at all of these fixed VLBI sites except Mojave are a part of the Eastern U. S. Strain Network. In addition to the fixed VLBI sites, six VLBI stations have been established in the strain network area using mobile VLBI. These stations are located at Miles City, MT; Platteville, CO; Leonard, OK; Bloomington, IN; New Carrollton, GA; and Austin, TX. Stations of the strain network were established at all six of these sites.

\section{OBSERVATIONAL ACTIVITIES}

Observations over the 45-station network given in Table 1 were performed in November and December 1987. The basic observing plan called for 3 days occupation of each of the 45 stations. It was hoped that enough GPS receivers would be available to complete observations over the network using three 3day observing periods. Three observing days at each station were selected because it was felt that at least 2 days of usable data were needed at each station to validate results, and that with $3 \mathrm{da}$ :- of observations, one would normally obtain at least 2 days of usable data. As may be seen from i ible 1, after three observing sessions, all but five stations of the network had been occupied. Two additional small observing sessions resulted in $\mathbf{4 4}$ of the $\mathbf{4 5}$ stations being occupied during the

November/December 1987 time period. The two CIGNET stations at Westford and Mojave observed over the entire period. The only station never occupied was the Dallas, Texas station. As will be discussed later, other observations are available, which can be used as initial epoch determinations for this station.

All data for this project were obtained using $\mathrm{Tl}-4100$ receivers with standard $\mathrm{Tl}-4100$ antennas. At each station, the antenna was plumbed over the measurement point on the monument using an optical plummet. Height of the antenna above the measurement point on the monument was measured both before and after each observing session using a graduated steel rod. Measurements of temperature, pressure, and humidity were recorded several times during each observing session.

Table 2 gives the typical observing scenario. This scenario gives the satellites observed for the group 1 observations. As may be seen, a total of five satellites were observed. Both amount of data and satellite geometry were far from optimal. From 4 to $51 / 2$ hours of data were typically obtained with $21 / 2$ to 3 hours of simultaneous tracking of four satellites during the middle of the observing period, and tracking of three satellites during the remainder of the time.

\section{GENERAL CHARACTERISTICS OF SOLUTION}

GPS observations consist, fundarnentally, of measurements of carrier phase of a satellite transmission (together with a time tag) for a number of equispaced (in time) epochs. These types of measurements are recorcied for several satellites simultaneously, i.e., the epochs of the measurements are identical in 
TABLE 1

STATION NAME

Alberg

Arp 2

Ashcoport

Astro

Austin

Beartown

Bloomington*

Bluffport

Bolton

Bravo

Brinkley

Bronson

Cheyenne

Dallas

Farm

FLNR

Freeman

Ft. Davis*

Furtrell

GP37

GP47

GP57

Greentank*

Hapgood

Houston

K169

Leonard*

Lime

Lincoln

Lubbock

Maryland Point*

Miles City*

New Carrollton*

NMB1

North Liberty

Pierre

Plattville*

Princeton

Richmond*

Rock

Stanport

Statesport

Waltport

Westford*

Williamson
STATIONS OF THE EASTERN U. S. STRAIN NETWORK ABBREVIATION

ALBU

ARP2

ASHC

ASTW

AUST

BEAR

BLOO

BLUF

BOLT

DROP

BRIN

BRON

1169

DALL

FARM

FLNR

FREE

HAR4

FUTZ

GP37

GP4?

GP57

T007

HAGO

HOUS

K169

LEON

LIMA

LINC

LUBR

MDPT

MILE

CARR

NMB1

NOLI

HYDE

PLAT

PRIN

TIME

ROCK

STAN

STAT

WALT

OCP3

WILL
STATE OF LOCATION

OBSERVATION GROUP(S)

Vermont 3

New York 4

Ohio 3

Virginia 3

Texas 1

Pennsylvania 3

Indiana 2, 4

Missouri 2

Ohio 4

Minnesota 1

Arkansas 1

Mississippi 1

Wyoming 1

Texas 1

Louisiana 1

Florida 2

Michigan 2

Texas 1

North Carolina 3

Tennessee 2

Tennessee 2

Tennessee 2

West Virginia 3

South Carolina 2

Texas 1

Maine 3

Oklahoma 1

Maine 3

Nebraska 1

Texas 1

Maryland 3

Montana 1

Georgia 2

New Mexico 1

lowa 1

South Dakota 1

Colorado 1

New Jersey 3

Florida 3,4

Wisconsin 1

Kentucky 4

North Carolina 4

South Carolina 2

Massachusetts $\quad 1,2,3,4$

Illinois

${ }^{\star}$ Collocated with VLBI stations 
TABLE 2

NOVEMBER 12-14 OBSERVING SESSION

OBSERVING SCENARIO AND SATELLITE AVAILABILITY

\begin{tabular}{||c|c|c|c|}
\hline UT Dates & Start UTC & Stop UTC & $\begin{array}{c}\text { Satellites } \\
\text { SV Numbers }\end{array}$ \\
\hline Nov. 12, 13, 14 & $11: 40$ & $13: 00$ & $6,8,11$ \\
& $13: 00$ & $14: 50$ & $6,8,9,11$ \\
& $14: 50$ & $15: 20$ & $8,9,11,12$ \\
& $15: 20$ & $17: 20$ & $9,11,12$ \\
\hline
\end{tabular}


time. For each satellite, the quantity recorded at the initial epoch is the fractional part of the current cycle. For succeeding epochs, the quantity recorded is the change in phase, given in terms of number of whole cycles plus a fractional part of a cycle. Thus, in geometric terms, what one has at each epoch is the distance from the receiver antenna to the satellite, expressed in units of cycles, minus a constant. The constant, which is the same at all epochs for a given satellite, is the unknown number of whole cycles to be added to the initial epoch partial cycle measurernent to give the distance from receiver to satellite at the time of the initial epoch measurement. The above statements would be strictly true if two conditions were met. The first condition would be for all satellite clocks and receiver clocks to be perfectly synchronized. The other condition would be for all refraction elfects to be absent. Since these conditions are not met, the failure to meet them must be taken care of in the reduction process.

The clock problem is taken care of by solving for differences in position between stations, rather than absolute station positions, and, thereby, being able to use as an observable a "double difference." Consider four measurements of phase made at the same epoch. Let $k_{11}$ and $k_{12}$ be measurements of phase by station 1 for signals from satellites 1 and 2 and $k_{21}$ and $k_{22}$ measuremerts by station 2 for signals from satellites 1 and 2 . The double difference observable formed is then

$$
D K^{d d}=\left(k_{11}-k_{12}\right)-\left(k_{21}-k_{22}\right)
$$

By differencing between satellites the quantities $\left(k_{11}-k_{12}\right)$ and $\left(k_{21}-k_{22}\right)$ are free of receiver clock errors since the receiver clock error is identical for measurements made at the same instant in time to two satellites. Similarly, by taking the difference between $\left(k_{11}-k_{12}\right)$ and $\left(k_{21}-k_{22}\right)$, i.e., differencing of measurements to the same satellites at the same instant in time, satellite clock errors are eliminated from the double difference observable.

With respect to refraction, two types of refraction must be considered, ionospheric refraction and tropospheric refraction. lonospheric refraction is taken care of by employing two frequencies and using yet a third type of differencing. The previous discussion assumed only a single frequency was broadcast by the GPS satellites. In fact, two frequencies are broadcast. Because ionospheric refraction is frequency dependent, one can record phase information from both frequencies and form an ionospheric refraction free residual, $\mathrm{DK}^{3 \mathrm{dd}}$, where:

$$
\begin{aligned}
& \mathrm{DK}^{30 d}=.435 \mathrm{Dk}^{10 d}-.236 \mathrm{DK}^{2 d d} \\
& \mathrm{Dk}^{10 d} \text { is the double difference phase observable of frequency } \mathrm{f}_{1} \\
& \text { and } \mathrm{DK}^{20 d} \text { is the double difference phase observable of frequency } \mathrm{f}_{2}
\end{aligned}
$$

The frequencies involved are:

$$
\begin{aligned}
& f_{1}=1571.4 \mathrm{MHz} \\
& f_{2}=1227.6 \mathrm{MHz}
\end{aligned}
$$

Final answers for high accuracy solutions over long baselines such as were required for this study employ the $\mathrm{DK}^{300}$ observable. For reasons that will be discussed below, it is also necessary to carry out solutions using the observables $\mathrm{Dk}^{10 d}$ and $\mathrm{DK}^{2 \mathrm{dd}}$. At NGS the nomenclature normally used in describing the solutions is to refer to $L_{1}, L_{2}$, and $L_{3}$ solutions when using respectively, the $D^{10 d}, D^{20 d}$ and $D^{30 d}$ observables. That nomenclature will be used in this report.

Tropospheric refraction is initially estimated using surface meteorological data (temperature, pressure, and humidity) recorded at the time of observation and employing the Marini refraction model. This model gives refraction in the form of a constant, commonly referred to as zenith delay, multiplied by a function of the elevation angle of the satellite as viewed from the observing station. The computer 
program used allows for improvements in initial estimates of the tropospheric refraction by allowing corrections to the zenith delay at stations to be unknowns in the solution.

The solution methodology is summarized in broad terms in the following discussion. The simplest sulution is one in which it is assumed that satellite positions as a function of time are known, and only two stations are involved. In this case, the known quantities, held fixed in the solutions, are the position of one of the two stations, and the satellite positions at each measurement epoch. The quantities estimated in the solution are then the position of the unknown station relative to the known station (Dx, Dy, Dz) and linear combinations of the initial epoch whole cycle counts. In forming the double difference residuals, one satellite is chosen as the reference satellite. Then the linear combinations of whole cycle counts at the initial epoch involve linear combinations of differences between the whole cycle count of the reference satellite and each of the other satellites in the solution. The zenith delay constant at one or both of the stations may also be included in the solution as an unknown.

A more complex solution is one in which a large number of stations observe during an observing session and three or more (preferably at least four) stations have known positions, a priori. These known positions may be due to results obtained previously from observations using other techniques such as VLBI and/or Satellite Laser Ranging (SLR). In this case, the unknowns determined in the solution could include (in addition to differential positions of one or more stations whose positions are unknown, linear combinations of initial epoch whole cycle counts, and corrections to computed zenith delays at stations) corrections to satellite position parameters. In the programs used at NGS, initial estimates of satellite positions as a function of time during an observing session of 4 to 6 hours in length are expressed for a given observation epoch in the form

$$
E\left(a, e, I, \Omega, w, M,\left(t_{e}-t_{o}\right)\right)+F\left(t_{e}\right),
$$

where $E$ gives the best estimate position for the satellite at the observation epoch, $t_{b}$ assuming ellipsoidal motion and $F\left(t_{e}\right)$ is the deviation from ellipsoidal motion at time $t_{e}$.

The location of the satellite due to ellipsoidal motion at a time $t_{e}$ is expressed as a function of shape of the best fitting ellipsoid (semi major axis, a, and ellipticity, e), orientation of the ellipsoid in space (inclination, $\mathrm{I}$, longitude of ascending node, $\mathbf{Q}$, and argument of perigee, $w$ ) and the mean motion $M$ of the satellite between the time of perigee passage $\left(t_{0}\right)$ and the observation epoch time $t_{e}$. In the solution one may solve for corrections to all, or some subset of elliptical parameters $a, e, I, \Omega, w, M$, and $t_{\text {. }}$.

\section{CYCLE SLIPS}

One additional factor complicates obtaining solutions from GPS observations. This complication is referred to as cycle slips. Consider the carrier phase for a single frequency broadcast by a single satellite and received by a single station. As mentioned previously, the observed quantity at all observation epochs after the first epoch is the total change in phase since the initial epoch observation. This total change in phase computed at a subsequent epoch is obtained by counting the number of whole cycles since the initial epoch and adding to it the partial phase measurement. For various reasons (such as temporary loss of lock due to obstruction of the satellite signal), there may be an error introduced in the whole cycle count. This error, called a cycle slip, will cause an abrupt offset in the observational residuals equal to an integer number of cycles. These cycle slips can usually be corrected for, using the knowledge that they are equal to an integer number of cycles. However, locating and correcting cycle slips is usually the most time consuming part of GPS data processing. 


\section{REDUCTION PROCEDURE}

The steps in reduction of GPS data used to produce the results reported here can be summarized as follows for each observing session:

1. Original GPS observations were transferred from cassette tapes to floppy disk, and then entered into the computer used for reduction.

2. Using a program designated ARGO, the required information for the data reduction was extracted from the raw observation files, and reformatted into files which could be used in the reduction programs.

3. Meteorologicai information and height of GPS antenna above the station monument were extracted from hard copy field records and entered into appropriate computer files, together with initial estimates of positions of all stations.

4. Appropriate weekly high accuracy satellite orbit files obtained from the Naval Surface Warfare Center (NSWC) were run through a preprocessing program to provide satellite position information in the correct format for use in the reduction programs.

5. The GPS observations, ancillary information, and orbit data were input to an initial reduction program named MERGE. The MERGE program performed the following primary functions: (a) computed tropospheric refraction corrections from the meteorological data observed in the field; (b) carried out gross cycle slip fixing (i.e., removed most cycle slips greater than 100 cycles); and (c) formatted the data for use in the subsequent reduction and refined cycle slip fixing programs.

6. A program designated CYFIX was run on each frequency, $L_{1}$ and $L_{2}$, independently to remove additional cycle slips with a more refined automatic cycle slip fixing routine.

7. The final reduction program, GPS22, was run on $L_{1}$ and $L_{2}$ data independently to obtain solutions. Observation residuals were then plotted, and used to identify and correct for remaining cycle slips. This procedure was iterated as required until all cycle slips were identified and corrected.

8. With cycle slips now corrected, GPS22 was used to perform an $L_{3}$ solution, If the $r \mathrm{~m} \mathrm{~s}$ residuals and the residual plots were satisfactory, this was a final solution. Often, however, it would be found at this stage that one or more cycle slips had been missed, and it would be necessary to go back to step 6 .

9. In performing the final solution, the parameters solved for were: station positions of the unknown stations, trospheric scale height parameters for each station, initial constants for all satellites (except the reference satellite) at all stations (except the reference station), and six orbit parameters (all except $t_{0}$ ) for all satellites.

\section{DESCRIPTION OF RESULTS}

Results from the reductions of the observations are best summarized in terms of baseline lengths and station positions obtained from the reductions of the 15 observing sessions involved. The derived station positions are given in Tables $1 \mathrm{~A}$ through $4 \mathrm{~A}$ of the Appendix. The baseline lengths are summarized in Tables $1 B$ through $4 B$. Table $1 C$ gives the positions of the reference stations used in the computations. Complete positioning results, in the form of computer printouts, are available from the NRC technical monitor or from the NGS, as are station descriptions. 
As may be seen from the Appendix, at least 2 days of reducible observations were obtained from 40 of the 45 stations of the Eastern Strain Network during the November/December 1987 time period. No useful data were obtained from the following stations:

\author{
Bravo, Minnesota \\ Dallas, Texas \\ Austin, Texas \\ Houston, Texas \\ Statesport, North Carolina
}

Failure to obtain data from the above five stations was the result of several different circumstances. All of the data from station Bravo were very noisy and could not be processed. The cause of this noise is not clear; it could have resulted from instrument problems or from noise due to operation of large radio frequency antennas at the site. Stations at Austin and Houston observed as scheduled and obtained data. However, it was found that the external cesium time standards to which the receivers were connected at these sites had not functioneJ properly and the data could not be used. Due to a last minute lack of equipment, the station at Dallas was never occupied. The Statesport station was occupied and observed as scheduled. However, the data could not be processed, presumably because of instrument problems.

Despite the lack of data from five sites during the November/December 1987 observing period, it should be possible to obtain initial epoch observations for all of these stations except Statesport using other observations. When it was determined during data reduction that no useable data had been obtained at station Bravo, remedial observations were scheduled. These observations were made in November 1988. At that time, GPS interconnections were made between stations Bravo, Rock, Freeman, and Bloomington. These observations are summarized in Table 3. Analysis of these data should allow positioning of Bravo unless the problem with the November 1987 observations was radio frequency noise at the site. If noise is the problem, this station must be abandoned and another site selected to replace it.

Positions for stations Austin, Dallas, and Houston should be derivable from data observed in 1985 and 1986. At that time, GPS observations were made at these stations and other stations in Texas, simultaneously with GPS observations at the fixed VLBI sites located at Ft. Davis, Westford, Richmond, Mojave, and Owens Valley. The State of Texas Highway Department is also currently reobserving the Austin, Dallas, and Houston sites using dual frequency Wild Magnavox receivers. All of the above data sets are available to NGS for analysis.

The intent was to have GPS observations from a minimum of four receivers collocated at VLBI sites during each observing session. Holding these stations' positions fixed at the VLBI derived position values, the GPS observations taken by them could be used to support orbit adjustment during data reduction. Because of the unexpected failures of the permanent GPS stations at the Mojave, Westford, and Richmond sites, data were not always available and this intent was not realized after the initial (group 1) observations. Table 4 indicates the VLBI sites from which GPS observations were available during each observing session. It will be noted that the data available for orbit adjustment were particularly poor for the group 2 observations. On one day only two collocated GPS stations obtained observations.

The observations undertaken in November 1988 were designed, not only to obtain a position for station Bravo, but also to provide a means for future improvement of the group 2 station positions reported here. Using the November 1988 observations, a position can be established for station Freeman by using the VLBI position of Bloomington and the position for station Rock obtained from the group 1 observations. Freeman could then be used as a station whose position is known to support orbit adjustment in a rereduction of the group 2 data, thereby improving the determination of positions of the other group 2 stations. It should also be possible to improve the group 3 results in the future. The 
TABLE 3

STATION OCCUPATIONS SEPTEMBER/OCTOBER 1988

\begin{tabular}{||c|c|c|c|c||}
\hline \multirow{2}{*}{$\begin{array}{c}1988 \\
\text { DAY }\end{array}$} & BRAVO & ROCK & FREEMAN & BLOOMINGTO \\
\cline { 2 - 5 } & $\mathrm{X}$ & $\mathrm{N}$ & $\mathrm{X}$ & $\mathrm{X}$ \\
\hline $9 / 28$ & $\mathrm{X}$ & $\mathrm{X}$ & $\mathrm{X}$ \\
$9 / 29$ & $\mathrm{X}$ & $\mathrm{X}$ & $\mathrm{X}$ & $\mathrm{X}$ \\
$9 / 30$ & & $\mathrm{X}$ & $\mathrm{X}$ & $\mathrm{X}$ \\
$10 / 5$ & & $\mathrm{X}$ & $\mathrm{X}$ & \\
$10 / 6$ & & & & \\
\hline
\end{tabular}

TABLE 4

REFERENCE STATIONS USED FOR SOLUTIONS

\begin{tabular}{|c|l||}
\hline OBSERVATION DAY & \multicolumn{1}{|c|}{ REFERENCE STATIONS } \\
\hline 316 & Ft. Davis, Mojave, Westford, Plattville \\
317 & $\begin{array}{l}\text { Ft. Davis, Mojave, Westford, Plattville } \\
\text { Ft. Davis, Mojave, Westford, Plattville }\end{array}$ \\
\hline 318 & New Carrollton, Bloomington, Mojave \\
321 & $\begin{array}{l}\text { New Carrollton, Bloomington, Westford } \\
\text { New Carrollton, Mojave }\end{array}$ \\
\hline 323 & Maryland Point, Mojave, Richmond, Westford \\
326 & $\begin{array}{l}\text { Maryland Point, Mojave, Richmond } \\
\text { Maryland Point, Mojave, Richmond }\end{array}$ \\
\hline 328 & Bloomington, Westford, Richmond \\
336 & Bloomington, Westford, Richmond \\
\hline 342 & Bloomington, Mojave, Richmond \\
343 & Bloomington, Mojave, Richmond, Westford \\
344 & Bloomington, Mojave, Richmond, Westford \\
\hline
\end{tabular}


Greenbank, West Virginia, station which took part in the group 3 observations is located at a fixed VLBI site. However, its position could not be held fixed for performing the reductions reported here because the differential position between the VLBI measurement point and the ground mark occupied by GPS were not available. However, the measurements necessary to obtain this local differential position have been made. Thus, when these measurements have been analyzed and the differential position determined, the Greenbank station can be the fourth station held fixed to improve orbit adjustment, and the group 3 results improved.

The group 1 results may be considered as an example of the type of accuracy attainable with GPS in the differential positioning mode when adequate data for orbit adjustment is available. Tables $1 \mathrm{~A}$ and $1 \mathrm{~B}$ summarize the repeatability of not only line length, but also position (latitude and longitude) for the group 1 observations. The deviations from the mean for repeat observations of latitude and longitude are shown in Figure 3. These deviations are plotted at real scale to emphasize the extraordinary accuracy of these results. The average deviation from the mean for the entire data set is $0.3 \mathrm{~cm}$ in latitude, $0.9 \mathrm{~cm}$ in longitude, and $3.0 \mathrm{~cm}$ in height. Since many of the baselines involved are in excess of $1,000 \mathrm{~km}$ in length, the horizontal position repeatability attained in this case is at about the 1 part in $10^{8}$ level.

During the group 1 observations, six VLBI sites were occupied. Only four were held fixed in the adjustment to allow orbit improvement. The other two sites, Leonard, Oklahoma, and Miles City, Montana, were allowed to adjust freely. To test the accuracy as well as the precision (i.e., repeatability) of the GPS results from group 1 data reductions, comparisons were made of GPS and VLBI determinations of the baselines between Ft. Davis, Texas, and the Leonard and Miles City stations. The results are given in Table 5. These comparisons show that it is possible to achieve GPS accuracies (as contrasted with precisions) of $1: 10^{8}$ in differential latitude determination and 1 to 2:10 in differential longitude determination over station separations of 1000 to $2000 \mathrm{~km}$.

Examination of Tables 1B-4B shows that for the other large observation groups (groups 2 and 3) the variations in line length determinations from day to day were at the few centimeter level provided at least three base stations were available to support orbit adjustment. This is only a slight decrease in accuracy from the results obtained from group 1 observations. However, as can be seen in Tables 1A-4A in Appendix $B$, the decrease in repeatability is much greater for the position components, i.e., latitude and longitude. The conclusion derived from these results is that three fixed stations are not adequate to maintain coordinate system orientation during solutions when the orbit is allowed to adjust.

\section{RELATION TO NAD 83 AND GRS-80}

The existing horizontal control in the United States is based on the North American Datum of 1983 (NAD 83) reference system. The reference system is defined by a reference coordinate system and a reference ellipsoid. In defining the NAD 83 reference coordinate system, the fixed VLBI stations in the United States were included in the adjustment. Because the VLBI was not used to define all parameters of the NAD 83 coordinate system, and because the current VLBI/SLR coordinate system has changed slightly since the NAD 83 adjustment, there is a difference between the current coordinate system used here and the NAD 83 coordinate system. Using VLBI station coordinates in the two systems, a seven parameter transformation (three translations, three rotations, and a scale) have been determined to go from the current system to NAD 83. These parameters are given in Table 6.

The reference ellipsoid used to express NAD 83 coordinates in terms of latitude and longitude is the GRS-80 ellipsoid. This ellipsoid has a semimajor axis of $6378.137 \mathrm{~m}$ and a flattening of $1 / 293.2$. Since GPS positioning is a geometric procedure, the heights produced are ellipsoid heights derived by subtracting from the geocentric radius vector computed in a GPS solution the radius vector to the ellipsoid at the latitude of the station. As a result, GPS ellipsoid heights are not directly comparable to heights derived from leveling (orthometric heights). An orthometric height is a height above the sea level 

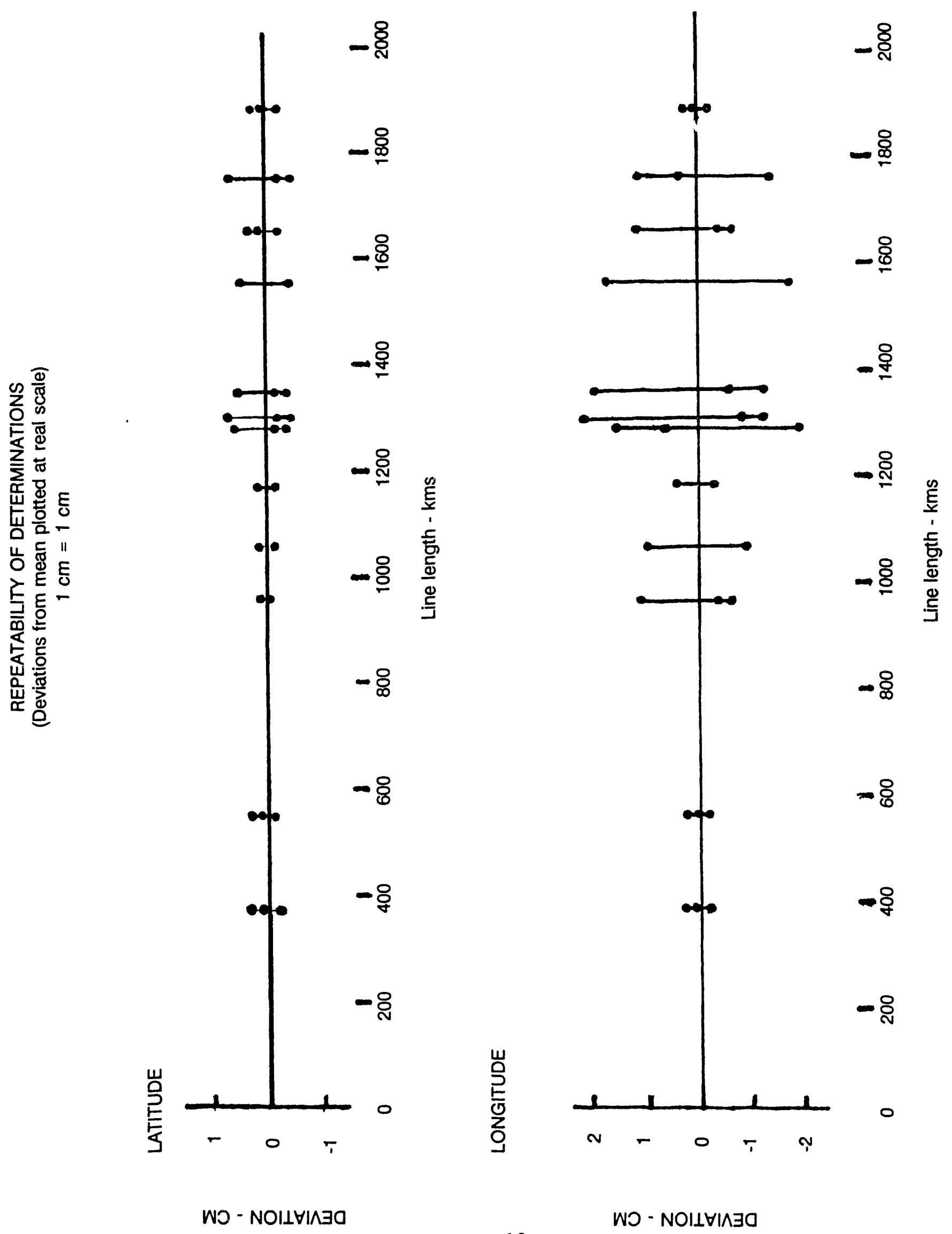

$m$
$\frac{1}{5}$
$\frac{1}{L}$
in 
TABLE 5

EVALUATION OF ACCURACY

DIFFERENCE BETWEEN MEAN GPS AND VLBI POSITIONS

MILES CITY

(1752 KM BASELINE)

\begin{tabular}{|c|c|c|}
\hline LATITUDE & LONGITUDE & HEIGHT \\
\hline $4.5 \mathrm{MM}$ & $8.2 \mathrm{MM}$ & $34.0 \mathrm{MM}$ \\
\hline
\end{tabular}

LEONARD

(957 KM BASELINE)

\begin{tabular}{|c|c|c|}
\hline LATITUDE & LONGITUDE & HEIGHT \\
\hline $1.8 \mathrm{MM}$ & $30.0 \mathrm{MM}$ & $47.0 \mathrm{MM}$ \\
\hline
\end{tabular}

TABLE 6

TRANSFORMATION PARAMETERS

FROM VLBI COORDINATE SYSTEM

TO NAD 83 SYSTEM

$$
\begin{gathered}
D x=x \text { translation }=1.055 \text { meters } \\
D y=y \text { translation }=2.069 \text { meters } \\
D z=z \text { translation }=0.426 \text { meters } \\
S c=\text { scale change }=-.096 \mathrm{ppm} \\
R x=\text { rotation about } x \text { axis }=.0215 \text { arc sec. } \\
R y=\text { rotation about } y \text { axis }=.0275 \text { arc sec. } \\
R z=\text { rotation about } z \text { axis }=.0010 \text { arc sec. }
\end{gathered}
$$


equipotential surface, i.e., the geoid. In the form of an equation, we have for a point on the earth's surface

$$
H=h+N
$$

where $\quad H=$ ellipsoid height

$h=$ orthometric height

$N=$ geoid height, i.e., height of the geoid relative to the ellipsoid

To directly compare levelirig derived orthometric heights and GPS derived ellipsoid heights, it is necessary to compute geoid heights. Geoid heights can be computed using integration of gravity anomalies over the surface of the earth. By using satellite derived gravity fields for long wavelength components, and local surface gravity measurements for local, short wavelength gravity variations, it is possible to compute geoid heights. Currently, accuracies in the range of \pm 5 to $10 \mathrm{~cm}$ are achievable in the United States. The National Geodetic Survey currently has a program aimed at improved computation methods and an enlarged gravity data base. This progran is aimed at achieving accuracies in the \pm 2 to $4 \mathrm{~cm}$. range. Because geoid height computations will never be perfect, comparisons of GPS derived height differences between stations with leveling derived orthometric height differences will never be as accurate as direct GPS vs. GPS comparison of height differences as a function of time.

\section{CONCLUSIONS AND RECOMMENDATIONS}

Examination of the Appendix demonstrates that results obtained for group 1 observations are more accurate than those for the other groups of observations. This is particularly true for baseline components. Table $1 \mathrm{~A}$ indicates that for the group 1 observations latitude and longitude are as accurate as baseline lengths given in Table 1B. However, as may be seen from the data presented in Appendix $B$, while the repeatability in baseline length is nearly as good as that of group 1 for some of the other groups, this is by no means the case for baseline components. The cause of repeatability in baseline length, but not in baseline component;, must lie in variation from day to day of the orientation of the coordinate system. The difference be ween group 1 observations and the observations providing answers from other groups lies in the number of stations available to support orbit adjustment, i.e., stalions whose positions are known a priori on the basis of VLBI. For all days of the group 1 observations, four stations (Mojave, I t. Davis, Westford, and Plattville) could be held fixed to support orbii adjustments.

Because of instrument problems either at the fixed VLBI stations (Mojave, Ft. Davis, Westford, Richmond) or at one of the mobile VLBI sites (Bloomington and New Carrollton) being occupied by GPS, there was only 1 day during the remaining observations after the group 1 observations when four stations could be held fixed. It seems clear that less than four stations cannot provide adequate orbit adjustment support to fix orientation. In the case of day 323 of group 2 observations, only two reference stations were available. As may be seen from Table 2B, less than three reference stations does not even support adequate line length determination. The conclusion that one can draw from the above result is that any future observations should be undertaken with the requirement that at least four GPS stations must be collocated at fixed or mobile VLBI sites.

Because of a desire to improve the results for baseline components for groups other than group 1, the question has been explored as to the possibility of other methods of reduction. Software is currently being developed to allow simultaneous reduction of all 3 days of observation of a station group. For such a reduction, the differential station positions would be unknowns that are common to all 3 days, while the orbit adjustment parameters can be day specific. This should allow for better separation of station position and orbit unknowns. 
In examining the results of these initial epoch measurements, it was clear that a change in observing strategy would be desirable in any future campaigns. The strategy used did not call for any overlapping between observation groups, other than the permanent GPS stations at the fixed VLBI sites. The result of this approach was that relatively closely spaced stations of the network are not directly connected. In retrospect, it seems clear this is not desirable, particularly since it has been shown that small coordinate system rotations are a possibility. Thus, any future observations should call for a more network like observational approach, with some subset of stations observed in any given observation group observed during another observation group.

A final recommendation is that at some time over the next 2 to 3 years reobservations should be made at the mobile VLBI sites at Miles City, Leonard, Bloomington, and New Carrollton in support of this program. The station at Plattville is also important, but it is anticipated that mobile VLBI observations will continue to be made at this site by NASA. 
APPENDIX

STATION POSITIONS AND LINE LENGTHS 
TABLE 1-A

GROUP 1

STATION POSITIONS

\begin{tabular}{|c|c|c|c|c|c|c|}
\hline \multicolumn{7}{|c|}{ STATION NAME } \\
\hline \multicolumn{3}{|c|}{ LATITUDE } & \multicolumn{3}{|c|}{ LONGITUDE } & \multirow{2}{*}{$\begin{array}{l}\text { ELLIP. } \\
\text { HEIGHT } \\
\text { (METERS) }\end{array}$} \\
\hline DEGREES & MINUTES & SECONDS & DEGREES & MINUTES & SECONDS & \\
\hline \multicolumn{7}{|l|}{ BRONSON } \\
\hline \multirow[t]{3}{*}{31} & \multirow[t]{3}{*}{17} & 44.53445 & 89 & 48 & 56.38799 & 47.3576 \\
\hline & & .53467 & & & .38896 & .4446 \\
\hline & & .53420 & & & .38748 & .4084 \\
\hline \multicolumn{7}{|l|}{ BRINKLEY } \\
\hline \multirow[t]{3}{*}{34} & \multirow[t]{3}{*}{53} & 1.58604 & 91 & 10 & 29.01988 & 29.0616 \\
\hline & & 1.58632 & & & .02022 & .0624 \\
\hline & & 1.58583 & & & .01862 & .0606 \\
\hline \multicolumn{7}{|l|}{ FARM } \\
\hline \multirow[t]{3}{*}{32} & \multirow[t]{3}{*}{45} & 20.70756 & 93 & 3 & 23.44214 & 81.3903 \\
\hline & & 20.70572 & & & 23.44062 & .3154 \\
\hline & & 20.70546 & & & 23.43975 & .3415 \\
\hline \multicolumn{7}{|l|}{ LINCOLN } \\
\hline \multirow[t]{3}{*}{40} & \multirow[t]{3}{*}{45} & 39.22306 & 96 & 42 & 25.15445 & 335.1534 \\
\hline & & 39.22344 & & & 25.15556 & .0768 \\
\hline & & 39.22306 & & & 25.15417 & .1063 \\
\hline \multicolumn{7}{|l|}{ LEONARD } \\
\hline \multirow[t]{3}{*}{33} & \multirow[t]{3}{*}{54} & 32.46598 & 95 & 47 & 42.24878 & 226.2389 \\
\hline & & 32.46597 & & & 42.24931 & .2265 \\
\hline & & 32.46585 & & & 42.24858 & .2244 \\
\hline \multicolumn{7}{|c|}{ NORTH LIBERTY } \\
\hline \multirow[t]{3}{*}{41} & \multirow[t]{3}{*}{46} & 19.28367 & 91 & 34 & 28.68851 & 204.7268 \\
\hline & & 19.28373 & & & 28.68903 & .6468 \\
\hline & & 19.28363 & & & 28.68828 & .6751 \\
\hline \multicolumn{7}{|l|}{ NMBI } \\
\hline \multirow[t]{3}{*}{35} & \multirow[t]{3}{*}{2} & 29.63628 & 106 & 36 & 52.19789 & 1597.9082 \\
\hline & & 29.63622 & & & 52.19783 & .9010 \\
\hline & & 29.63635 & & & 52.19804 & .9481 \\
\hline \multicolumn{7}{|l|}{ ROCK } \\
\hline 43 & 12 & 1.96763 & 89 & 30 & 5.37511 & 287.5758 \\
\hline & & 1.96772 & & & 5.37560 & .4810 \\
\hline & & 1.96760 & & & 5.37444 & .5231 \\
\hline MILLS CITY & & & & & & \\
\hline 46 & 23 & 47.03106 & 105 & 51 & 38.96188 & 703.9345 \\
\hline & & 47.03142 & & & 38.96215 & .8324 \\
\hline & & 47.03123 & & & 38.96152 & .8712 \\
\hline
\end{tabular}




\begin{tabular}{|c|c|c|c|c|c|c|}
\hline \multicolumn{7}{|c|}{ LUBBOCK } \\
\hline \multirow[t]{3}{*}{33} & \multirow[t]{3}{*}{31} & 27.75627 & 101 & 48 & 14.11503 & 937.9730 \\
\hline & & 27.75620 & & & 14.11487 & .9695 \\
\hline & & 27.75607 & & & 14.11493 & .9172 \\
\hline \multicolumn{7}{|c|}{ CHEYENNE } \\
\hline \multirow[t]{2}{*}{41} & \multirow[t]{2}{*}{8} & 2.61949 & 104 & 52 & 2.00519 & 1867.2941 \\
\hline & & 2.61946 & & & 2.00507 & .3496 \\
\hline \multicolumn{7}{|l|}{ PIERRE } \\
\hline 44 & \multirow[t]{2}{*}{23} & 7.03950 & 100 & 18 & 41.02277 & 531.1099 \\
\hline & & 7.03924 & & & 41.02153 & .1388 \\
\hline
\end{tabular}


TABLE 2-A

GROUP 2

STATION POSITIONS

\begin{tabular}{|c|c|c|c|c|c|c|}
\hline \multicolumn{7}{|c|}{ STATION NAME } \\
\hline \multicolumn{3}{|c|}{ LATITUDE } & \multicolumn{3}{|c|}{ LONGITUDE } & \multirow{2}{*}{$\begin{array}{l}\text { EUUP. } \\
\text { HEIGHT } \\
\text { (METERS) }\end{array}$} \\
\hline DEGREES & MINUTES & SECONDS & DEGREES & MINUTES & SECONDS & \\
\hline \multicolumn{7}{|l|}{ ASTRO } \\
\hline \multirow[t]{2}{*}{38} & \multirow[t]{2}{*}{12} & 127.42493 & 77 & 22 & 24.35727 & 34.542 \\
\hline & & .42207 & & & .35026 & .802 \\
\hline \multicolumn{7}{|l|}{ BLUFFPORT } \\
\hline \multirow[t]{3}{*}{36} & \multirow[t]{3}{*}{46} & 0.04149 & 90 & 19 & 26.15715 & 68.810 \\
\hline & & .04062 & & & .15937 & .732 \\
\hline & & .04392 & & & .15629 & .558 \\
\hline \multicolumn{7}{|l|}{ FLNR } \\
\hline \multirow[t]{3}{*}{29} & \multirow[t]{3}{*}{34} & 29.47726 & 82 & 20 & 7.61638 & -10.682 \\
\hline & & .47733 & & & .61667 & .527 \\
\hline & & .47707 & & & .62039 & .895 \\
\hline \multicolumn{7}{|l|}{ FREEMAN } \\
\hline \multirow[t]{3}{*}{43} & \multirow[t]{3}{*}{31} & 22.36192 & 84 & 5 & 26.02083 & 167.859 \\
\hline & & .36003 & & & .01369 & 168.141 \\
\hline & & .35389 & & & .00207 & .595 \\
\hline \multicolumn{7}{|l|}{ GP37 } \\
\hline \multirow[t]{2}{*}{35} & \multirow[t]{2}{*}{54} & 56.81883 & 85 & 13 & 4.09964 & 221.435 \\
\hline & & .81746 & & & .09640 & .624 \\
\hline \multicolumn{7}{|l|}{ GP47 } \\
\hline \multirow[t]{3}{*}{35} & \multirow[t]{3}{*}{35} & 23.75611 & 89 & 35 & 7.91298 & 53.575 \\
\hline & & .75509 & & & .91462 & .532 \\
\hline & & .75557 & & & .91421 & .825 \\
\hline \multicolumn{7}{|l|}{ GP57 } \\
\hline \multirow[t]{2}{*}{35} & \multirow[t]{2}{*}{12} & 21.05711 & 88 & 29 & 58.24275 & 155.194 \\
\hline & & .05717 & & & .24920 & .357 \\
\hline \multicolumn{7}{|l|}{ HAPGOOD } \\
\hline \multirow[t]{3}{*}{34} & 3 & 27.34573 & 80 & 34 & 18.02641 & 13.979 \\
\hline & & .34697 & & & .02677 & 14.091 \\
\hline & & .34613 & & & .02403 & .0318 \\
\hline WILLIAMSO & & & & & & \\
\hline 37 & 44 & 54.03067 & 89 & 0 & 51.67745 & 109.011 \\
\hline & & .02987 & & & .67778 & 108.935 \\
\hline WALTPORT & & & & & & \\
\hline 32 & 55 & 16.56914 & 80 & 38 & 18.47765 & -4.0432 \\
\hline & & .56945 & & & .47674 & .0683 \\
\hline
\end{tabular}


TABLE 3-A

GROUP 3

STATION POSITIONS

\begin{tabular}{|c|c|c|c|c|c|c|}
\hline \multicolumn{7}{|c|}{ STATION NAME } \\
\hline \multicolumn{3}{|c|}{ LATTUDE } & \multicolumn{3}{|c|}{ LONGITUDE } & \multirow{2}{*}{$\begin{array}{l}\text { EUUP. } \\
\text { HEIGHT } \\
\text { (MEIERS) }\end{array}$} \\
\hline DEGREES & MINUTES & SECONDS & DEGREES & MINUTES & SECONDS & \\
\hline \multicolumn{7}{|l|}{ ALBERG } \\
\hline \multirow[t]{3}{*}{44} & \multirow[t]{3}{*}{54} & 29.31253 & 73 & 17 & 28.49040 & 36.758 \\
\hline & & .31179 & & & .48947 & .781 \\
\hline & & .31473 & & & .49380 & .655 \\
\hline \multicolumn{7}{|c|}{ ASHCOPORT } \\
\hline \multirow[t]{3}{*}{41} & \multirow[t]{3}{*}{46} & 47.92860 & 80 & 42 & 2.07992 & 241.363 \\
\hline & & .92603 & & & .07509 & .219 \\
\hline & & .92912 & & & .07836 & .234 \\
\hline \multicolumn{7}{|l|}{ BEARTOWN } \\
\hline \multirow[t]{3}{*}{40} & \multirow[t]{3}{*}{4} & 59.24159 & 76 & 0 & 59.23800 & 302.165 \\
\hline & & .24181 & & & .23882 & .129 \\
\hline & & .24273 & & & .23968 & .067 \\
\hline \multicolumn{7}{|l|}{ FURTRELL } \\
\hline \multirow[t]{3}{*}{36} & \multirow[t]{3}{*}{20} & 14.81336 & 77 & 9 & 7.89446 & -6.796 \\
\hline & & .82013 & & & .89492 & .799 \\
\hline & & .81913 & & & .89446 & .883 \\
\hline \multicolumn{7}{|c|}{ GREEN BANK } \\
\hline \multirow[t]{3}{*}{30} & \multirow[t]{3}{*}{26} & 14.11269 & 79 & 49 & 54.55640 & 790.223 \\
\hline & & .11217 & & & 55533 & .164 \\
\hline & & .11309 & & & .55655 & .176 \\
\hline \multicolumn{7}{|l|}{ K169 } \\
\hline \multirow[t]{3}{*}{44} & \multirow[t]{3}{*}{24} & 16.08784 & 68 & 0 & 43.514:36 & -18.824 \\
\hline & & .08906 & & & .54664 & .903 \\
\hline & & .09144 & & & .54806 & -19.044 \\
\hline \multicolumn{7}{|l|}{ LIME } \\
\hline \multirow[t]{3}{*}{46} & \multirow[t]{3}{*}{8} & 0.62809 & 68 & 4 & 55.21858 & 191.217 \\
\hline & & .63227 & & & .22367 & .372 \\
\hline & & .63078 & & & .22433 & .384 \\
\hline \multicolumn{7}{|c|}{ PRINCETON } \\
\hline 40 & 23 & 54.76514 & 74 & 39 & 47.25348 & 2.101 \\
\hline & & .75537 & & & .25435 & 1.998 \\
\hline & & .76649 & & & .25615 & 1.926 \\
\hline
\end{tabular}


TABLE 4-A

GROUP 4

STATION POSITIONS

\begin{tabular}{|c|c|c|c|c|c|c|}
\hline \multicolumn{7}{|c|}{ STATION NAME } \\
\hline \multicolumn{3}{|c|}{ LATITUDE } & \multicolumn{3}{|c|}{ LONGTIUDE } & \multirow{2}{*}{$\begin{array}{l}\text { EUPP. } \\
\text { HEIGHT } \\
\text { (METERS) }\end{array}$} \\
\hline DEGREES & MINUTES & SECONDS & DEGREES & MINUTES & SECONDS & \\
\hline \multicolumn{7}{|l|}{ BOLTON } \\
\hline 39 & 59 & 29.64438 & 83 & 09 & 15.22273 & 237.976 \\
\hline & & .64514 & & & .22338 & .887 \\
\hline \multicolumn{7}{|l|}{ ARP 2} \\
\hline 43 & 59 & 29.38421 & 76 & 01 & 18.90521 & 61.045 \\
\hline & & .38199 & & & .89973 & .421 \\
\hline & & .38343 & & & .90353 & .400 \\
\hline \multicolumn{7}{|c|}{ STATESPORT } \\
\hline 35 & 45 & 50.99968 & 80 & 57 & 6.84624 & 258.854 \\
\hline & & .99955 & & & .84702 & 9.023 \\
\hline & & .99944 & & & .84967 & .035 \\
\hline
\end{tabular}


TABLE 1-B

LINE LENGTH DETERMINATIONS

OBSERVATION GROUP 1

\begin{tabular}{||l|r|r|r||}
\hline \multirow{2}{*}{ STATION NAME } & \multicolumn{3}{|c|}{ LINE LENGTH (meters) } \\
\cline { 2 - 4 } & DAY 316 & DAY 317 & DAY 318 \\
\hline BRONSOM & $1,348,789.553$ & .535 & .564 \\
BRINKLEY & $1,282,945.259$ & .252 & .283 \\
FARM & $\star$ & $1,057,256.564$ & .584 \\
LINCOLN & $1,297,303.971$ & .958 & .970 \\
LEONARD & $957,146.442$ & .428 & .441 \\
NORTH LIBERTY & $1,654,782.992$ & .974 & .988 \\
NMBI & $548,614.002$ & .000 & .006 \\
ROCK & $1,885,425.309$ & .288 & .312 \\
MILES CITY & $1,752,057.514$ & .512 & .507 \\
LUBBOCK & $378,833.555$ & .555 & .550 \\
CHEYENNE & $\star \star$ & $1,166,456.353$ & .353 \\
PIERRE & $\star \star$ & $1,555,412.446$ & .447 \\
\hline
\end{tabular}

* INSUFFICIENT DATA FOR SOLUTION

* NO DATA OBTAINED

LINE LENGTHS COMPUTED RELATIVE TO FT. DAVIS 
TABLE 2-B

LINE LENGTH DETERMINATIONS

OBSERVATION GROUP 2

\begin{tabular}{||l|c|c|c||}
\hline \multirow{2}{*}{ STATION NAME } & \multicolumn{3}{|c|}{ LINE LENGTH (meters) } \\
\cline { 2 - 4 } ASTRO & DAY 321 & DAY 322 & DAY 323** \\
BLUFFPORT & $\star$ & $865,867.913$ & 8.023 \\
FLNR & $592,279.740$ & .766 & .800 \\
FREEMAN & $513,397.142$ & .143 & .085 \\
GP 37 & $1,106,740.999$ & .979 & .853 \\
GP 47 & $\star$ & $223,182.312$ & .270 \\
GP 57 & $467,524.803$ & .824 & .832 \\
HAPGOOD & $\star$ & $360,499.052$ & .200 \\
WILLIAMSON & $423,466.742$ & .741 & .806 \\
WALTPORT & $582,496.403$ & .385 & $*$ \\
BRAVO & $422,783.341$ & $\star$ & $\star 361$ \\
\hline
\end{tabular}

* NO USEFUl DATA OBTAINED

** ONLY TWO REFERENCE STATIONS AVAILABLE

LINE LENGTHS COMPUTED RELATIVE TO NEW CARROLLTON 
TABLE 3-B

LINE LENGTH DETERMINATIONS OBSERVATION GROUP 3

\begin{tabular}{||l|r|r|r||}
\hline \multirow{2}{*}{ STATION NAME } & \multicolumn{3}{|c|}{ LINE LENGTH (meters) } \\
\cline { 2 - 4 } ALBERG & DAY 326 & DAY 327 & DAY 328 \\
ASHCOFORT & $795,804.308$ & .297 & .330 \\
BEARTOWN & $480,044.662$ & $.525^{\star}$ & .647 \\
FURTRELL & $216,972.608$ & .603 & .617 \\
GREENBANK & $214,965.419$ & .467 & .497 \\
K169 & $227,234.692$ & .665 & .696 \\
LIME & $1,019,134.612$ & .589 & .598 \\
PRINCETON & $1,142,809.667$ & .696 & .655 \\
\hline
\end{tabular}

* CAUSE FOR BAD RESULT UNKNOWN

LINE LENGTHS COMPUTED RELATIVE TO MARYLAND POINT 
TABLE 4-B

LINE LENGTH DETERMINATIONS

OBSERVATION GROUP 4

\begin{tabular}{|c|c|c|c||}
\hline \multirow{2}{*}{ STATION NAME } & \multicolumn{3}{|c||}{ LINE LENGTH (meters) } \\
\cline { 2 - 4 } & DAY 336 & DAY 337 & DAY 338 \\
\hline BOLTON & $298,136.944$ & .933 & $\star$ \\
STANPORT & $\star$ & \multicolumn{3}{|c||}{ LINE LENGTH (meters) } \\
\hline \multirow{2}{*}{ STATION NAME } & DAY 342 & DAY 343 & DAY 344 \\
\cline { 2 - 4 } & $1,021,850.771$ & .876 & .821 \\
ARP 2 & $619,560.636$ & .632 & .583 \\
\hline STATESPORT & & & \\
\hline
\end{tabular}

* NO USEFUL DATA OBTAINED

LINE LENGTHS COMPUTED RELATIVE TO BLOOMINGTON 
TABLE 1-C

REFERENCE STATION POSITIONS

DERIVED FROM VLBI

\begin{tabular}{|c|c|c|c|c|c|c|}
\hline \multicolumn{7}{|c|}{ STATION NAME } \\
\hline \multicolumn{3}{|c|}{ LATTTUDE } & \multicolumn{3}{|c|}{ LONGITUDE } & \multirow{2}{*}{$\begin{array}{l}\text { EUUP. } \\
\text { HEIGHT } \\
\text { (METERS) }\end{array}$} \\
\hline DEGREES & MINUTES & SECONDS & DEGREES & MINUTES & SECONDS & \\
\hline
\end{tabular}

\begin{tabular}{|c|c|r|c|c|r|r|}
\hline MOJAVE & \\
\hline 35 & 19 & 53.60676 & 116 & 53 & 17.34449 & 904.553 \\
\hline
\end{tabular}

\begin{tabular}{|c|l|l|l|l|l|l|}
\hline \multicolumn{6}{|l|}{ WESTFORD } \\
\hline 42 & 36 & 47.96306 & 71 & 29 & 36.00635 & 86.329 \\
\hline
\end{tabular}

FT. DAVIS

\begin{tabular}{|l|l|l|l|l|l|l|}
\hline 30 & 38 & 9.60446 & 103 & 56 & 49.11649 & 1583.508 \\
\hline
\end{tabular}

\begin{tabular}{|c|l|l|l|l|l|r|}
\hline PLATTVILLE & \\
\hline 40 & 10 & 58.06244 & 104 & 43 & 34.83818 & 1501.351 \\
\hline
\end{tabular}

\begin{tabular}{|c|c|c|c|c|r|r|}
\hline NEW CARROLLTON & \\
\hline 33 & 34 & 21.19125 & 85 & 6 & 34.49384 & 299.607 \\
\hline
\end{tabular}

\begin{tabular}{|c|c|c|c|c|r|r|}
\hline \multicolumn{1}{|l|}{ BLOOMINGTON } \\
\hline 39 & 10 & 45.65345 & 86 & 29 & 54.28572 & 217.760 \\
\hline
\end{tabular}

\begin{tabular}{|c|c|c|c|c|c|c|}
\hline \multicolumn{7}{|c|}{ MARYLAND POINT } \\
\hline 38 & 22 & 24.22672 & 77 & 13 & 53.45068 & -26.144 \\
\hline \multicolumn{7}{|c|}{ RICHMOND } \\
\hline 25 & 36 & 50.75137 & 80 & 23 & 2.62933 & -19.298 \\
\hline
\end{tabular}




\begin{tabular}{|c|c|}
\hline $\begin{array}{l}\text { BIBLIOGRAPHIC DATA SHEET } \\
\text { (See instructions on the reverse) }\end{array}$ & 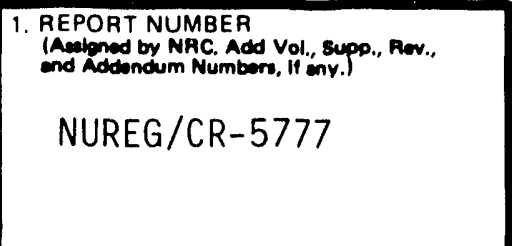 \\
\hline \multirow{2}{*}{$\begin{array}{l}\text { 2. TITLE AND SUBTITLE } \\
\text { Global Positioning System Measurements Over a Strain } \\
\text { Monitoring Network in the Eastern Two-Thirds of the } \\
\text { United States }\end{array}$} & \\
\hline & $\begin{array}{l}\text { September } 1991 \\
\text { 4. FINOR GRANT NUMBER } \\
\text { D1749 }\end{array}$ \\
\hline \multirow[t]{2}{*}{$\begin{array}{l}\text { 5. AUTHOR(S) } \\
\text { W. E. Strange }\end{array}$} & $\begin{array}{l}\text { 6. TYPE OF REPORT } \\
\text { Technical }\end{array}$ \\
\hline & $\begin{array}{l}\text { 7. PERIOD COVERED (Inclusive Dates) } \\
\text { Apri } 1 \quad 1987 \text {-August } 1991\end{array}$ \\
\hline \multicolumn{2}{|c|}{ 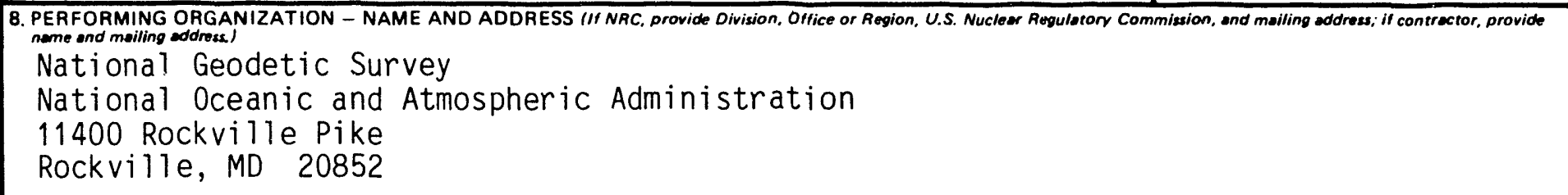 } \\
\hline \multicolumn{2}{|c|}{ 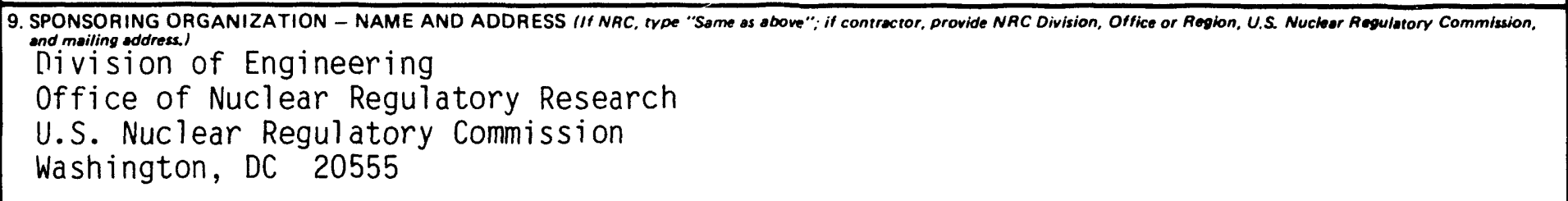 } \\
\hline \multicolumn{2}{|l|}{ 10. SUPPLEMENTARY NOTES } \\
\hline \multicolumn{2}{|c|}{ 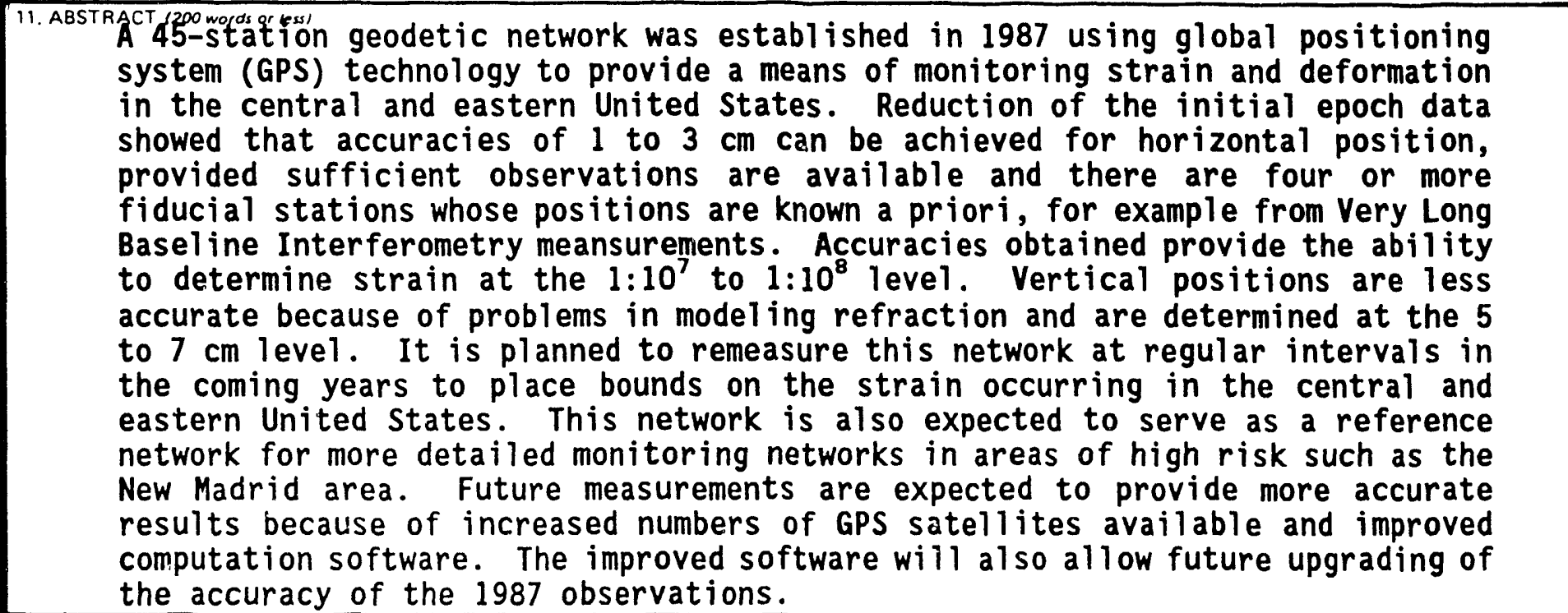 } \\
\hline \multirow{4}{*}{$\begin{array}{l}\text { 12. KEY WORDS/DESCR!PTORS (List words or phroses that will assist receoschers in locating the report.) } \\
\text { Global Positioning Svstem (GPS) } \\
\text { Very Long Baseline Interferometry (VLBI) } \\
\text { strain monitoring network } \\
\text { Central and Eastern U.S. }\end{array}$} & \\
\hline & 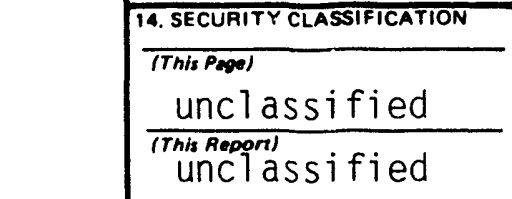 \\
\hline & 15. NUMBEA OF PAGES \\
\hline & \\
\hline
\end{tabular}



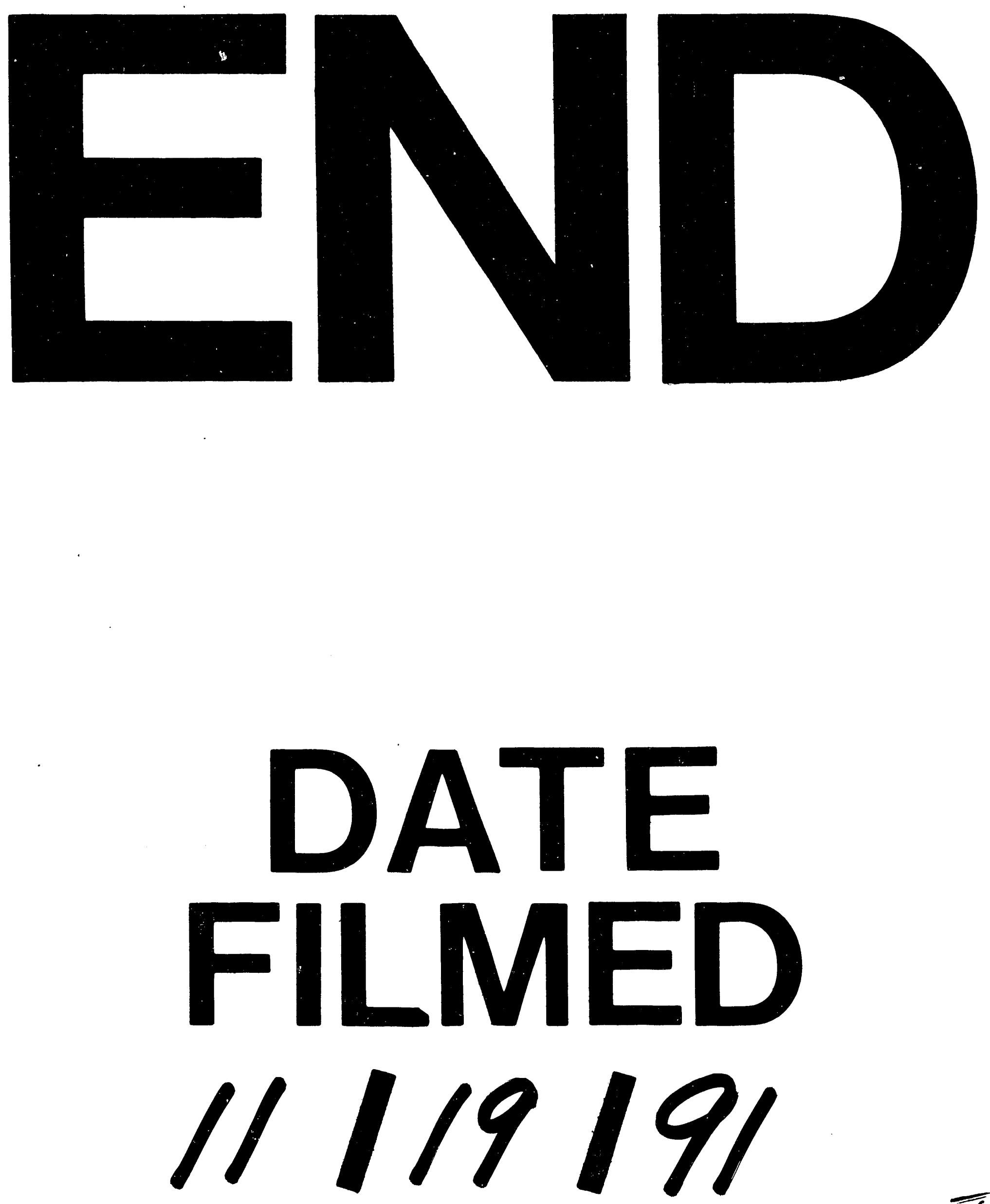

II 
